\title{
Dehydration of Ethanol/Water Mixture Using Pervaporation and Vapor Permeation Technique
}

\author{
A. Boontawan ${ }^{1}$, P. Schausberger ${ }^{2}$, P. Bösch ${ }^{3}$ \& A. Friedl $4^{4}$ \\ ${ }^{1}$ Biofuel Production from Biomass Research Unit, School of Biotechnology, Institute of Agricultural Technology, \\ Suranaree University of Technology, Nakhon Ratchasima, 30000, Thailand \\ 2,3\&4 Department of Chemical Engineering, Vienna University of Technology, Getreidemarkt 9/166, A-1060, \\ Vienna, Austria
}

\begin{abstract}
The demand of bio-ethanol to substitute petroleum-based fuel is continuously increasing, and economic aspect has become an important factor in the design of ethanol dehydration plants. Since it forms an azeotrope at $89.4 \mathrm{~mole} \%$, $78^{\circ} \mathrm{C}$ and atmospheric pressure, further dehydration process is difficult and expensive. In this work, a composite membrane using modified poly vinyl alcohol (PVA) as the active separating layer, and poly-acrylonitrite (PAN) as a supportive layer was employed. Two membrane processes, pervaporation (PV) and vapor permeation (VP) system, were investigated for their dehydration performances in order to produce motor fuel grade ethanol (MFGE). The effects of feed temperature, feed pressure, feed composition, module temperature, and permeate pressure were compared for both systems, and also discussed in detail. Total flux, ethanol flux, and water flux as well as separation factor were also calculated. In general for both systems, the water fluxes decreased dramatically as the feed side ethanol concentrations increased. However, the pervaporation system was affected the most, and this is because of the low diffusivity of water in ethanol. For the separation of azeotrope, water fluxes between $0.06-1.17 \mathrm{~kg} / \mathrm{m}^{2} / \mathrm{hr}$ with separation factor of about 100 were observed in VP whilst the value of $0.10-0.22 \mathrm{~kg} / \mathrm{m}^{2} / \mathrm{hr}$ were obtained with $\mathrm{PV}$. In conclusion, VP has advantages over PV system in terms of separation performances and simplicities of the process.
\end{abstract}

Keywords: Pervaporation, vapor permeation, motor fuel grade ethanol (MFGE), poly vinyl alcohol (PVA) membrane, diffusion

\subsection{INTRODUCTION}

Ethanol is the most promising future biofuel due to its high energy value, and its simplicity of fermentation process. Due to an American standard, the amount of remaining water must be lower than $0.8 \mathrm{wt} . \%$ in order to produce motor fuel grade ethanol (MFGE) [1]. However, the latest European standard reduces the water

\footnotetext{
* Correspondence to: A. Friedl (email: afriedl@mail.zserv. tuwien.ac.at)
}

content to as low as $0.3 \%$ wt. $\%$ which make to separation process even more expensive [3]. Ethanol can be recovered from fermentation broth by mean of distillation, but it is commonly known that ethanol forms azeotrope with water at $89.4 \mathrm{~mole} \%$, (96 wt.\%) through which more anhydrous ethanol can not be produced. Azeotropic distillation is a way to break the azeotrope for production of MFGE. However, energy saving has become an important factor for dehydration of ethanol mixture due to rising energy cost, thus make the azeotropic distillation 
not economical viable [10]. Membrane separation as an alternative dehydration process has been developed to replace this energy consuming process. Pervaporation (PV) and vapor permeation (VP) are processes in which a fluid stream containing two or more miscible components is fed to one side of a membrane whilst a vacuum or inert gas is applied to the other side of the membrane [7]. In PV system, the feed side is in a form of liquid whilst the feed is applied as a vapor phase for the latter case. In VP system, the separating component just has to permeate through the membrane therefore the problem of supplying the heat of vaporization can be avoided. In addition, the system seems to be suitable to separate water at the top of fractionation columns where the vapor feed can be supplied directly to the membrane module [14].

In this work, a commercial composite membrane prepared from modified poly(vinyl alcohol) (PVA) as a selective layer and polyacrylonitrile (PAN) as a supportive layer was employed. PVA is often used in the dehydration of water-ethanol mixtures because it exhibits a good hydrophilic property. In addition, it also shows good chemical and physical stabilities, and low manufacturing cost [13]. The purpose of this study is to investigated the hydrophilic membrane for its dehydration performances of water-ethanol mixtures for both pervaporation and vapor permeation system.

\subsection{THEORY}

The membrane performance can be described by permeate flux $J\left(\mathrm{~kg} \cdot \mathrm{m}^{-2} \cdot \mathrm{h}^{-1}\right)$ and separation factor $\alpha$ which can be defined as follow;

$$
J=\frac{W(\mathrm{~kg})}{A\left(m^{2}\right) \cdot t(h)}
$$

Where $W$ is the weight of the permeate, $A$ is the membrane area, and $t$ is the time, respectively.

$$
\alpha=\frac{w_{P, H_{2} \mathrm{O}} / w_{F, H_{2} \mathrm{O}}}{w_{P, E t O H} / w_{F, E t O H}}
$$

Where $w_{F}$ and $w_{P}$ are the weight fraction of water and ethanol in the feed and permeate side respectively.
Based on the solution-diffusion model, the mass transport of component $i$ in pervaporation system $\left(\right.$ mole. $\mathrm{s}^{-1}$ ) can be written in terms of the difference in partial pressure as followed,

$$
m_{i, p}=A \cdot Q_{i} \cdot \Delta p_{i}
$$

Where $A$ is the membrane area $\left(\mathrm{m}^{2}\right), Q_{i}$ is the permeance $\left(\mathrm{mol} \cdot \mathrm{m}^{-2} \cdot \mathrm{s}^{-1} \cdot \mathrm{Pa}^{-1}\right)$, and $\Delta p_{i}$ is the driving force across the membrane $(\mathrm{Pa})$ which can be expressed as followed,

$$
\Delta p_{i}=x_{i, F} \cdot \gamma_{i} \cdot p_{i}^{*}-x_{i, P} \cdot P_{P}
$$

In this case, $x_{i, F}$ is the mole fraction of component $i$ in the feed side, $\gamma_{i}$ is the activity coefficient of $i$ in the feed side determined using UNIQUAC equation, $p_{i}^{*}$ is the saturated vapor pressure of $i$ estimated by Antoine vapor pressure equation, $x_{i, p}$ is the mole fraction of $i$ in the permeate side, and $p_{P}$ is the permeate pressure, respectively [11]. In vapor permeation, the $\Delta p_{i}$ of equation (4) is the difference in partial vapor pressure of $i$ between feed $\left(p_{i, F}=x_{i, F} P_{F}\right)$ and permeate side $\left(p_{i, P}=x_{i, P} P_{P}\right)$, where $P_{F}$ is the total feed pressure [5].

\subsection{METHODS}

Separation experiments for pervaporation and vapor permeation were conducted on a lab scale set up as shown in Figure 1. A composite PVA/ PAN membrane supplied by GKSS (Geesthacht, Germany) with a surface area of $0.0288 \mathrm{~m}^{2}$ $(0.16 \mathrm{~m} \times 0.18 \mathrm{~m})$ was placed in a module, and temperature was controlled by re-circulating silicone oil through jacket surrounding the membrane module. For pervaporation, a gear pump was employed to re-circulate the feed with the flow rate for up to $120 \mathrm{~L} \cdot \mathrm{h}^{-1}$. Permeate pressure was kept low using a vacuum pump, and the permeate vapor was collected using cold traps immersed in liquid $\mathrm{N}_{2}$. The permeate was sampled periodically to determine the flux and ethanol composition. The permeation rate was measured gravimetrically by weighing the permeate sample collected over a period of time whilst determination of ethanol concentrations in both feed and permeate were carried out using a density meter (Mettler Toledo, Switzerland) 

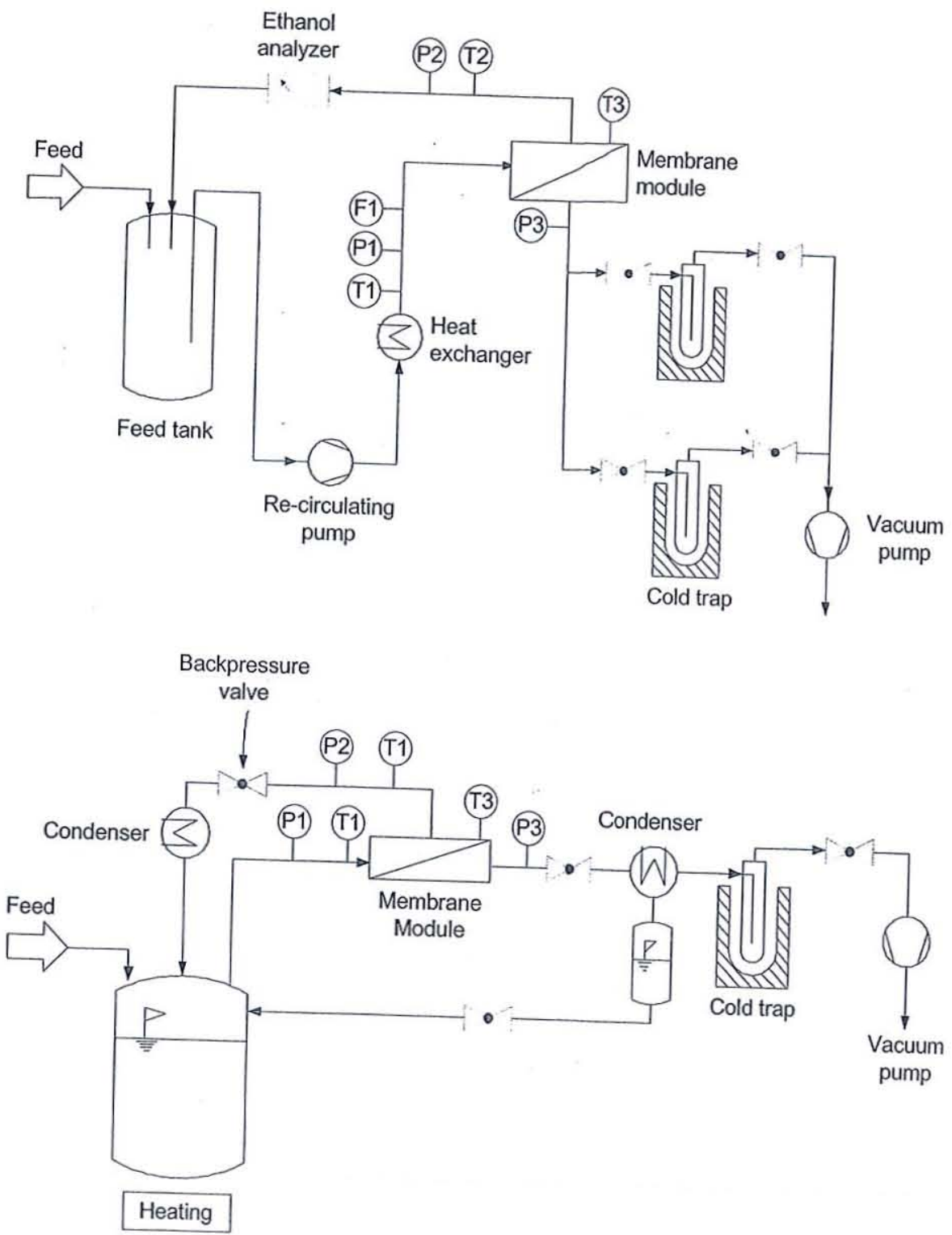

Figure 1 Schematic diagramme of apparatus for pervaporation (a) and vapor permeation (b)

with an accuracy of $\pm 0.00001 \mathrm{~g} . \mathrm{cm}^{-3}$. For vapor permeation experiment, the liquid feed was firstly heated in a pressurized vessel, and the vapor feed then enter the membrane module. The value of error is estimated to be in the range of $(8 \%$ of the determined values by triplicate experiments.

\subsection{RESULTS AND DISCUSSIONS}

\subsection{Pervaporation}

PVA membranes have been employed in pervaporation system for separation dehydration 
Table 1 Comparison of PV performance of PVA membranes with literatures

\begin{tabular}{cccccc}
\hline $\begin{array}{c}\text { Temperature } \\
\text { (K) }\end{array}$ & $\begin{array}{c}\text { Feed Mass fraction } \\
\text { of EtOH }\end{array}$ & $\begin{array}{c}\text { Total flux } \\
\left(\mathbf{k g} \cdot \mathrm{m}^{-2} \cdot \mathbf{h}^{-1}\right)\end{array}$ & $\begin{array}{c}\text { Water flux } \\
\left(\mathbf{k g} \cdot \mathrm{m}^{-2} \cdot \mathbf{h}^{-1}\right)\end{array}$ & $\alpha$ & Reference \\
\hline 343 & 0.92 & 0.11 & 0.015 & 150 & {$[4]$} \\
323 & 0.95 & $n a^{*}$ & 0.03 & 185 & {$[13]$} \\
343 & 0.85 & 0.10 & na & 77 & {$[8]$} \\
348 & 0.94 & 0.47 & 0.36 & 110 & This work \\
\hline
\end{tabular}

"na $=$ Not applicable

of organic solutions. This is because of their excellent hydrophilic characteristic, and good physical stability. In general, PVA membranes allow high permeability for water, and can be operated at temperature for up to $140^{\circ} \mathrm{C}$. Comparison between the membrane used in this experiment and other PVA membranes is given in Table 1.

The influence of feed water content on fluxes and separation factors in pervaporation are illustrated in Figure 2. It is shown that total, ethanol, and water fluxes decrease with decreasing feed water concentration. The total fluxes decrease from 0.82 to $0.07 \mathrm{~kg} \cdot \mathrm{m}^{-2} \cdot \mathrm{h}^{-1}$ as the water mass fractions in the feed decrease from 0.1 to 0.005 . For ethanol and water, it is clearly seen that water fluxes decrease dramatically whilst ethanol fluxes slightly decrease with decreasing of water content. A sharp decline in water flux across the membrane is clearly due to

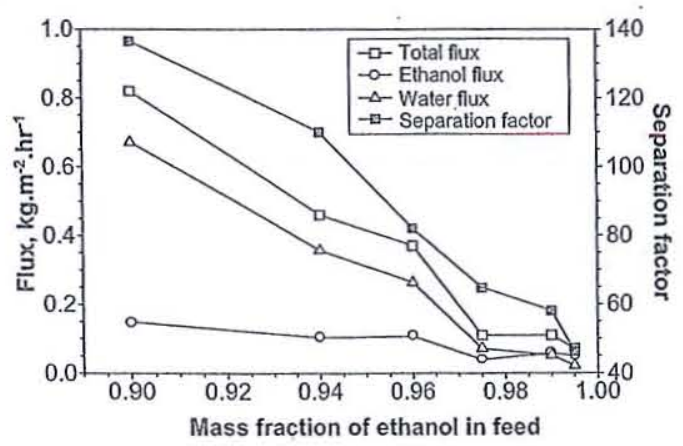

Figure 2 Performance of the PVA/PAN membrane during pervaporation experiment as a function of feed water content, T $348 \mathrm{~K}$, Flow rate $50 \mathrm{~L} \cdot \mathrm{h}^{-1}$, vacuum pressure $10 \mathrm{mBar}$ a reduction of driving force in Equation 3. This is a major disadvantage of membrane processes when the concentration of the separating component is decreasing in the feed side. However, this system shows an excellent removal of water from the feed mixture for up to 0.96 mass fraction of ethanol in the feed. For separation factor, it is shown that (decreases with decreasing water content in the feed. Ethanol flux increases with increasing water content in the feed side. The reason for this phenomenon is probably due to swelling effect of the PVA selective layer. Although the membrane is cross-linked, it swells in some degree especially at high water content thus allows ethanol molecules to transport across the selective layer more easily resulting in higher flux of ethanol [6].

Figure 3 shows the effect of operating temperature on the separation performances. Permeation experiments were carried out at

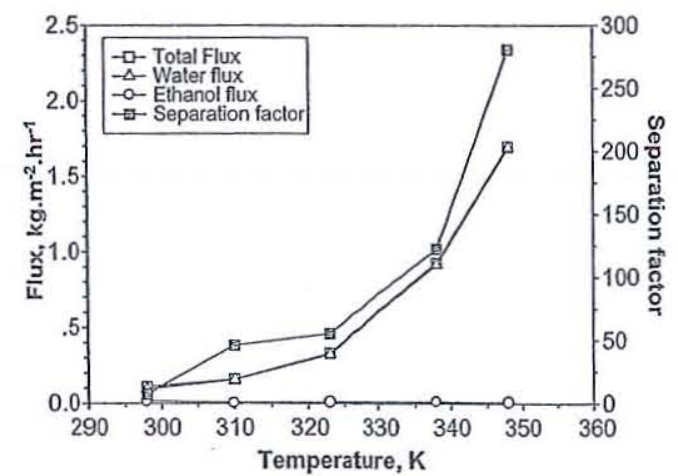

Figure 3 The influence of operating temperature on fluxes and separation factor from 298 to $348 \mathrm{~K}$ in pervaporation with 0.53 mass fraction of ethanol in the feed side. Vacuum $25 \mathrm{mBar}$, Flow rate $50 \mathrm{~L} . \mathrm{h}^{-1}$ 
different temperatures from 298 to $348 \mathrm{~K}$, and membrane performances were also investigated in terms of fluxes and separation factor. For the membrane studied here, a high permeation rate of water is accompanied by an increasing in operating temperature whilst ethanol permeability is relatively constant. The water fluxes range from $0.1 \mathrm{~kg} \cdot \mathrm{m}^{-2} \cdot \mathrm{h}^{-1}$ to $1.6 \mathrm{~kg} \cdot \mathrm{m}^{-2} \cdot \mathrm{h}^{-1}$ for the investigated temperatures. The increasing in water fluxes shows a typical Arrhenius type of relation. According to the free volume theory [7], the thermal motion of polymer chains in the amorphous region creates momentary free volume. As the temperature increases, the frequency and the amplitude of the polymer chain motion increase resulting in larger free volume, and allow permeating molecules to penetrate more freely. The membrane shows a good thermal stability when the system was performed at temperature up to $348 \mathrm{~K}\left(75^{\circ} \mathrm{C}\right)$. Separation factor increases with an increasing operating temperature indicating that the membrane will work much better at higher operating temperature.

\subsection{Vapor Permeation}

Application of the composite PVA/PAN membrane from GKSS in ethanol dehydration was also investigated using vapor permeation experiment at operating pressure between 1.5$3.5 \mathrm{bar}$, and module temperature between 356 $418 \mathrm{~K}\left(83-145^{\circ} \mathrm{C}\right)$. The retentate (product) flow was controlled by a back pressure valve with the flow rates between $0.1-1.5 \mathrm{~kg} \cdot \mathrm{h}^{-1}$. Separation of water and ethanol is governed by preferential absorption into the cross-linked polymer, and mass transfer characteristic is also affected by operating conditions. In this work, operating parameters on separation performances were investigated including the effect of feed ethanol mass fractions, feed and downstream pressures, and operating temperatures.

The effect of operating pressure and initial feed ethanol concentration on water flux is shown in Figure 4. The experimental results show that the water fluxes increase with increasing feed water content, and also increasing of water partial pressure in the feed stream. The highest water

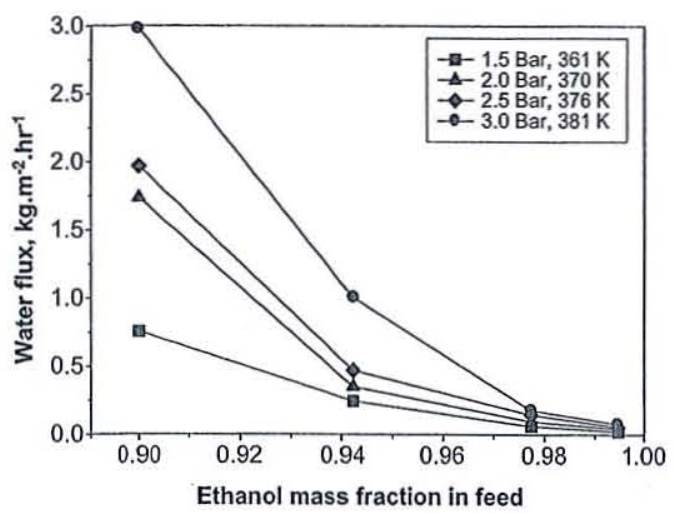

Figure 4 Effects of feed pressures and feed compositions on water fluxes, $20 \mathrm{mBar}$ vacuum pressure

flux obtained from the experiment at 0.1 mass fraction water content was approximately 3.0 $\mathrm{kg} . \mathrm{m}^{-2} \cdot \mathrm{h}^{-1}$ at the total feed pressure of $3.0 \mathrm{Bar}$. Despite high water fluxes can be obtained, the water fluxes decrease rapidly at higher ethanol concentration. The gradual reduction of permeate water fluxes at all operating conditions is clearly due to the decreasing water content in the feed side resulting in decreasing in the partial vapor pressure of water. At the mass fraction of feed water content 0.005 ( $0.5 \mathrm{wt} . \%)$, water fluxes for all experiments are not significantly different, and are in the range between $0.025-0.078 \mathrm{~kg} \cdot \mathrm{m}^{-2} \cdot \mathrm{h}^{-1}$.

The effect of down stream pressure on water fluxes is shown in Figure 5. All experiments were carried out at the vapor feed ethanol concentration between 0.84 to 0.9947 mass fraction whilst the feed pressure was kept constant at 2.5 Bar. In general, the lower the downstream pressure applied to the membrane, the higher the water flux can be obtained. This is simply due to the lower boiling point of water caused by low vacuum pressure. For the mass fraction of vapor feed ethanol at 0.9947, water fluxes do not changed significantly with the vacuum pressures applied, and are in the range between 0.1-0.05 $\mathrm{kg} \cdot \mathrm{m}^{-1} \cdot \mathrm{h}^{-1}$. For the other experiments, vacuum pressure plays an important role on water permeation through the selective layer. The most influential region is in the range for up to 100 mbar. This is because the boiling point of water 


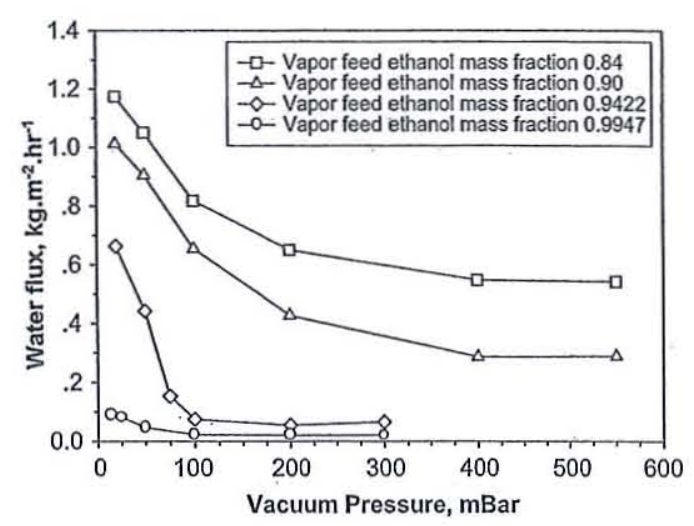

Figure 5 Effect of vacuum pressure on water fluxes at different feed ethanol compositions. 2.5 Bar feed pressure

significantly reduces at pressure lower than this value. However, application of very low vacuum requires a large amount of energy input, and also needs a large vacuum pump resulting in higher investment cost. Therefore, optimization between a high water flux and energy consumption is essential for engineer to design the dehydration plant. In addition, high energy for cooling is required for a very low vacuum applied.

\subsection{CONCLUSIONS}

Water can be successfully separated from ethanol/ water mixture in order to produce MFGE using both pervaporation and vapor permeation systems. PVA has shown a good separating characteristic, and allows high water flux whilst a majority of ethanol is retained in the retentate stream. For both PV and VP systems, the permenace of water across the selective layer depends on many operating parameters including partial feed pressure, feed flow rate, downstream pressure, and temperature. In PV, where the feed side is supplied as liquid phase, the system suffers from diffusion in boundary layer especially at a very high ethanol feed content. This is because the effect of concentration polarization on the membrane surface. In addition, low diffusivity of water in ethanol solution also plays an important role for the low permeance. In contrast with pervaporation, the feed side is in vapor phase for vapor permeation system. It has no phase change during permeation from the feed to the permeate side, therefore, the problem of supplying heat of vaporization can be avoided. In addition, the feed vapor can be pressurized in order to obtain high water flux. However, water flux for both PV and VP severely affect by the partial water pressure in the feed side especially at the low water concentration (from $1.0 \mathrm{wt} . \%$ ).

\section{ACKNOWLEDGEMENTS}

The contribution of T. Brinkmann of GKSS Research Centre Geesthacht GmbH, Institute of Polymer Research, Max-Planck-Straße 1, 21502 Geesthacht, Germany is greatly appreciated.

\section{REFERENCES}

[1] ASTM International 2004. Standard Specification for Denatured Fuel Ethanol for Blending with Gasoline for use as Automotive Spark Ignition Engine Fuel. D4806

[2] Brinkmann, T., K. Ebert, H. Pingel, A. Wenzlaff, and K. Ohlrogge. 2004. Process Alternatives through use of Organicinorganic Composite Membranes for Vapor Rermeation. Chem. Ing. Tech. 76: 15291533.

[3] DIN EN 15692. 2008. Ethanol as a Blending Component for Gasoline Determination of Water Content - Karl Fischer Potentiometric Titration Method. German version prEN 15692.

[4] Gimenes, M.L., L. Liu, and X. Feng. 2007. Sericin/poly(vinyl alcohol) Blend Membranes for Pervaporation Separation of Ethanol/water Mixtures. J. Membr. Sci. 295: 71-79.

[5] Gmehling, J., U. Onken, and G. Kreysa. 2003. Vapor-Liquid Equilibrium Data Collection - Aqueous System. Vol 1, Part 1c. In:Dechema Data Series, Frankfurt am Main, DECHEMA.

[6] Hayashi, H., S. Yuzaki, T. Kawanishi, N. Shimizu, and T. Furukawa. 2000. An Efficient Ethanol Concentration Process by 
Vapor Permeation through Asymmetric Polyimide Membrane. J. Membr. Sci. 177: 233-239.

[7] Huang, R.Y.M. 1991. Pervaporation Membrane Separation Processess. Amsterdam: Elsevier.

[8] Hyder, M.N., R.Y.M. Huang, and P. Chen. 2008. Effect of Selective Layer Thickness on Pervaporation of Composite Poly(vinyl alcohol)-poly(sulfone) Membranes. $J$. Membr. Sci. 318: 387-396.

[9] Jiraratananon, R., A. Chanachai, and R.Y.M. Huang. 2002. Pervaporation Dehydration of Ethanol-water Mixtures with Chitosan/hydroxyethylcelluluse (CS/ HEC) Composite Membranes II. Analysis of Mass Transport. J. Membr. Sci. 199: 211222.

[10] Matsuura, T. 1994. Synthetic Membrane and Membrane Separation Processes. Florida: CRC Press.
[11] Ried, R.C., J.M. Prausnitz, and B.E. Poling. 2000. The Properties of Gases and Liquids. McGraw Hill.

[12] Sato, K., K. Sugimoto, and T. Nakane. 2008. Mass-production of Tubular NaY Zeolite Membranes for Industrial Purpose and their Application to Ethanol Dehydration by Vapor Permeation. J. Membr. Sci. 319: 244-255.

[13] Wei, Y.-M., Z.-L. Xu, F.A. Qusay, and K. Wu. 2005. Polyvinyl Alcohol/Polysulfone (PVA/ PS) Hollow Fiber Composite Membranes for Pervaporation Separation of Ethanol/ Water Solution. J. Appl. Polym. Sci. 98: 247254.

[14] Yeom, C.K., and K.-H. Lee. 1997. Vapor Permeation of Ethanol-water Mixtures using Sodium Alginate Membranes with Crosslinking Gradient Structure. J. Membr. Sci. 135: 225-235. 